\title{
Research Paper: The Effectiveness of Video Modeling on Social Skills of Children with Autism Spectrum Disorder
}

\author{
Mohammad Ashori ${ }^{*} \mathbb{\oplus}$, Seyyedeh Somayyeh Jalil-Abkenar ${ }^{2} \mathbb{C}$ \\ 1. Department of Psychology and Education of Children With Special Needs, Faculty of Education and Psychology, University of Isfahan, Isfahan, Iran. \\ 2. Department of Psychology and Education of Exceptional Children, Faculty of Psychology and Education, University of Tehran, Tehran, Iran.
}

\begin{tabular}{|c|c|}
\hline $\begin{array}{l}\text { Use your device to scan } \\
\text { and read the article online }\end{array}$ & \\
\hline 口blar. & Clteation: Ashori, M., \& Jalil-Abkenar, S., S. (2019). The Effectiveness of Video Modeling on Social Skills of Children with \\
\hline rastin & Autism Spectrum Disorder. Journal of Practice in Clinical Psychology, 7(3), 159-166. http://dx.doi.org/10.32598/jpcp.7.3.159 \\
\hline listor & doil'http://dx.doi.org/10.32598/jpcp.7.3.159 \\
\hline
\end{tabular}

\section{(i) (8)}

Article info:

Received: 10 Jan 2019

Accepted: 25 May 2019

Available Online: 01 Jul 2019

Keywords:

Autism Spectrum Disorder, Social skills, Social interaction

\section{ABSTRACT}

Objective: The present study aimed at investigating the effectiveness of video modeling on social skills of children with Autism Spectrum Disorder (ASD).

Methods: The current experimental study with pre-test, post-test design and control group was conducted on 24 male children with ASD aged 6-8 years from two special schools. The samples were selected by random sampling method and randomly divided into experimental and control groups, each group consisted of 12 children. In the experimental group video modeling was used in 16 sessions, while the control group did not participate in this program. Gilliam Autism Rating Scale 2 (GARS-2) was used to diagnose ASD and Autism Social Skills Profile (ASSP) to assess social skills in children with ASD. The data were analyzed using multivariate analysis of covariance with SPSS V. 24.

Results: The obtained results showed that video modeling training had a positive and significant effect on social skills of children with ASD in the experimental group $\left(\mathrm{F}_{2.21}=28.170, \mathrm{P}<0 / 001\right)$.

Conclusion: These findings supported the effectiveness of video modeling on social skills of children with ASD. Therefore, this program can be used to improve social skills of such children and plan to provide video modeling training program for them, which has particular importance.

\section{* Corresponding Author:}

Mohammad Ashori, PhD.

Address: Department of Psychology and Education of Children With Special Needs, Faculty of Education and Psychology, University of Isfahan,

Isfahan, Iran.

Tel: +98 (31) 3793548

E-mail:m.ashori@edu.ui.ac.ir 


\section{Highlights}

- Video modeling training had a positive effect on the social skills of children with Autism Spectrum Disorder (ASD).

- There are significant differences between the control and experimental (children with ASD that participated in video modeling training program) groups concerning the scores of social skills.

- These changes of the score are due to the effect of video modeling training program in the experimental group.

\section{Plain Language Summary}

Children with ASD are a group of children with special needs. Problems and impairments in the social interaction, communication skills, repetitive and stereotyped patterns of behaviors are common characteristics of these children. Inappropriate social skills may impede children's development and increase the risk of social withdrawal, rejection, and isolation. It seems that video modeling training program improves many problems in these children. Video modeling can be used to train academic skills, social skills, self-help skills, and other necessary skills. The present research was conducted on 26 male children with ASD from two special schools in Tehran to examine the effect of video modeling training program on the social skills of these children. Video modeling training program led to the improvement of social interaction, social participation, appropriate social behaviors and social skills of children with ASD.

\section{Introduction}

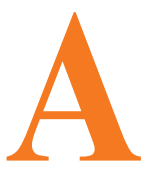

utism Spectrum Disorder (ASD) is one of the neuro-developmental disorders (Butchart et al., 2017). Children with ASD have problems in the social interaction, communication skills, repetitive and stereotyped patterns of behaviors, and interests of activities across multiple contexts (Besler \& Kurt, 2016). ASD is a common lifelong neurological developmental condition characterised by qualitative impairments in the social interaction and communication, engagement in routines and rituals, and hyper sensory or hypo sensory sensitivities (American Psychiatric Association, 2013; Spain, Sin, Linder, McMahon, \& Happé, 2018).

The prevalence of ASD has a special importance. The population of subjects with ASD is growing dramatically worldwide today (Bottini, 2018). In 2014, the estimation of children with ASD was 1 in 68, nearly a 120\% increase from 1 in 150 in 2000 (Loomes, Hull, \& Mandy, 2017). ASD symptoms can be observed around the age of three; however, symptoms across individuals can greatly vary. As the difficulties and impairments in social communication and interaction are the primary characteristics for children with ASD, a lack of social skill can lead them to a social isolation or withdrawal situations (Wong et al., 2015).
The importance of social skills development is critical. Such deficits may impede children development and increase the risk of social withdrawal and isolation (Matson, Dempsey, \& LoVullo, 2009). Children socially withdrawn may be rejected by peers, thus impeding social inclusion (Kagohara et al., 2013). Their isolation affects their overall educational experience. Professionals, teachers, peers, and others can be very effective in promoting the social skills of children with ASD using specific intervention strategies (Barnard-Brak, IveyHatz, Ward, \& Wei, 2014).

In other words, symptoms of ASD can be managed and treated using a variety of resources and techniques. Behavioral modification techniques are the most preferred methods to managed the symptoms and signs of ASD (Maddox, Miyazaki, \& White, 2016). Applied Behavior Analysis (ABA) is currently known to be the preferred method of treatment for ASD (Ross, 2007). ABA uses Discrete Trial Training (DTT), a teaching method for those diagnosed with ASD.

DTT is structured and repetitive, and encompasses learning opportunities that involve an antecedent, the learner's response, and a consequence (Wong et al., 2015). In fact, there are many strategies utilized in training and managing children with ASD. Many of these methods focus on using visual and concrete signs to help increase acquisition of skills. Some of these strategies include DTT, role-playing, and modeling. Modeling is an important training method for children with special 
needs such as children with ASD. Modeling allows the child to observe the desired behavior before teaching occurs in order to enhance the chances of acquisition (Ross, 2007).

Children with ASD do not always interact or play appropriately compared to their peers within the same age range. A child may not be able to engage in play areas that involve pretending, and imitating others. Children with this disorder have difficulties interacting in socially accep table ways. Using video modeling is an education technique which is created according to observational learning theory (Wong et al., 2015). Video modeling is a method of education where a target behavior is observed and learned through demonstration through a video clip. Video modeling can be used to train self-help skills, social skills, academic skills, incidental, and basic skills (Ross, 2007).

In some studies skills for using resources such as shopping, ATM withdrawal, and fast food ordering skills were taught with video modeling (Alberto, Cihak, \& Gama, 2005). Matson (2009) stated that many children with ASD may attend better to a model presented by video modeling than a life model demonstrating the skill. The goal of this type of teaching is to have the child observe a model of the desired behavior that is as realistic as possible. Children with ASD have a greater chance at learning a desired skill or target response when they are taught realistic scenarios that are similar to the natural environment (Besler \& Kurt, 2016).

Many studies report on the benefits and importance of video modeling for children, especially for children with special needs (Besler \& Kurt, 2016; Aldi et al., 2016). Children with ASD may lack social or emotional reciprocity. These children are in more risking condition due to their limited opportunities to participate in community and society. They have a few opportunities to engage in playing with their peers and social activities due to their impairments in social skills and social interactions. More important, not much attention is paid to children with ASD, even though many specialists are beginning to focus on problems of children with ASD in Iran. Now, although treatment is not available for ASD, some interventions and treatments can improve social skills of these children.

Video modeling plays a critical role in influencing children's lives, and this is important for children with ASD since it can help them improve both their social skills, and communication and social interaction. Therefore, the current study aimed at examining the effect of video modeling on the social skills of children with ASD.

\section{Methods}

The present study used experimental method by pretest, post-test design and control group. Participants were 24 ASD 6-8 years old male children enrolled in the elementary schools in Tehran during the academic year 2017-2018. There are nine elementary schools for students with ASD in Tehran. Subjects were selected by random sampling method. From the list of elementary schools, two schools were randomly selected. Participants were selected from those schools and randomly divided into two experimental and control groups, each group consists of 12 children.

All participants were Persian speakers. As for SocioEconomic Status (SES) parent of children came from moderate SES backgrounds. Inclusion criteria for subjects were having ASD with high performance (Intelligence quotient between 70 and 85), aged 6-8 years, first or two grade of school, and living with parents. Subjects were excluded from the research if there was evidence of a neuro-developmental disorders except ASD, and that they currently had a similar program. The current study was approved by Ethics Committee of Exceptional Education Organization in Iran. The importance of the study was explained to mothers of children. Also, informed consent was obtained from mothers of participants. The assessment tools of the current study were Gilliam Autism Rating Scale 2 (GARS-2) and Autism Social Skills Profile (ASSP).

The Autism Rating Scale 2 was developed by Gilliam in 2005. GARS-2 was used to diagnose ASD. This scale is a behavior checklist designed for 3-22-year-old children and adolescents based on DSM-IV diagnostic criteria for ASD. This scale consists of 42 questions (0126 scores) and three subscales (social interaction, communication, stereotyped behaviors). Each subscale has 14 items (0-42 scores). The questionnaire was scored based on Likert scale from 0 to 3 . This scale is based on direct observation and interviews with parents and teachers of children with ASD completed and widely used in educational programs and research. In the current study, mothers of subjects completed this scale. Cronbach's alpha coefficient of the Persian version of GARS-2 was above 0.70 (Samadi \& McConkey, 2014). Cronbach's alpha coefficient of this scale is reported 0.88 , and the constructed validity with the Modified list in Childhood Autism (MCAT) for stereotyped behaviors, communication, social interaction subscales and total scores were 
$0.77,0.79,0.83$ and 0.86 , respectively (Ahmadi, Safari, Hemmatian, \& Khalil, 2011).

The Autism Social Skills Profile (ASSP) was developed by Bellini and Hopf in 2007. ASSP is designed to assess social functions of children with ASD. This scale consists of three subscales (social interaction, social participation, and appropriate social behaviors). The ASSP is a four-point Likert scale including 48 questions and can be completed by teachers or parents in 15-20 minutes. Cronbach's alpha coefficient reported for social interaction, social participation, appropriate social behaviors, and total scores were 0.92, 0.89, 0.85 and 0.93 , respectively. Also test-retest reliability was 0.89 , 0.86, 0.86 and 0.90, respectively (Bellini \& Hopf, 2007). Internal consistency of the current study ranged from $\alpha=0.83$ to $\alpha=0.92$, and the test-retest reliability ranged from 0.74 to 0.97 (Moghim-Islam, PourmohammadrezaTajrishi, \& Haghgou, 2014).

In the first stage of the study, subjects were screened for IQ by Raven colure progressive matrices test, and ASD by GARS-2. ASSP was completed by mothers for all subjects (both groups) and scores were considered as Pre-test. Then, experimental group participated in 16 video modeling sessions (three times a week and one session a day) and the control group stayed in waiting list and only participated in common programs of school. The researcher prepared a task analysis of building a lego train before the intervention. This lego train consisted of 51 pieces. Task analysis of a Lego train is presented in Table 1.

Table 1. The building a lego train

\begin{tabular}{|c|c|}
\hline Stage & Activity \\
\hline 1 & Pick up parts of the lego with red wheels. \\
\hline 2 & Place the locomotive face so that its hole is in front of the lego part. \\
\hline 3 & Place the piece number one behind the train. \\
\hline 4 & Place the red lego with the four holes behind part number one. \\
\hline 5 & Place the lego with coal on top of lego with the four holes, with its windows in the sides. \\
\hline 6 & Take the lego with green wheels. \\
\hline 7 & Place one of the log-shaped legos. \\
\hline 8 & Place the second log-shaped lego on the top of the first log-shaped lego. \\
\hline 9 & Place a third log-shaped lego on the top of other log-shaped legos already attached. \\
\hline 10 & Place a log car behind the pink locomotive. \\
\hline 11 & Take the part of lego with brown wheels. \\
\hline 12 & Place one of rock-shaped parts to first four holes. \\
\hline 13 & Place the second rock-shaped part next to the part of other log-shaped already installed. \\
\hline 14 & Place the rock car to log car. \\
\hline 15 & Place two orange parts on the top of one another. \\
\hline 16 & Place the other two yellow parts on top of one another. \\
\hline 17 & Place the yellow part with the orange parts to shape a bridge. \\
\hline 18 & Attach the bridge in front of the train. \\
\hline 19 & Drive the train toward the bridge with saying chug chug. \\
\hline 20 & Move by train under the bridge. \\
\hline
\end{tabular}


Before training sessions, the researcher and her assistant prepared the video clip and brought children into the classroom after providing a prompt to secure the children's attention, for example, are you ready for watching a video clip now? Researcher received a visual or verbal sign from the children that they are saying yes or nodding, Researcher used verbal reinforcement for the children; for example, by saying great or cheer. After playing the video clip, the researcher checked if the children were watching this video. If they did not look at the scene, the researcher or her assistant verbally reminded them (e.g. by saying watch the film or look at the screen), or gave a partially physical prompt (e.g. kindly turning his head towards the screen or pointing to it) and made sure that the children were looking. When the video clip was over, the children were verbally reinforced for looking at the screen appropriately (for example, by saying you are doing well or well done) and the children were directed to the range where the lego was located so that he could do the task. This drew children's attention (Are you ready to do what you saw?) and provided instructions for this task (Make a train from legos).

The researcher waited for the children to complete each of the identified steps in the analysis of tasks with five seconds for each step and verbally reinforced correct answers (for example, saying that you are doing well or well done). Researcher stopped this work (Enough for today, alright, we continue next session). When children responded incorrectly at any steps, ended the session. In the end of session, the researcher reinforced children for their cooperation and participation verbally (Thanks). Intervention sessions were continued until children could build a lego train.
Thus, researcher trained video modeling program to the experimental group, while the control group did not participate in any special treatment. In the final stage of research, each of the two groups were assessed by ASSP as the post-test. The data were analyzed using multivariate analysis of covariance with SPSS V. 24.

\section{Results}

The mean age of the subjects in the experimental and control groups was $7.17(\mathrm{SD}=0.67)$ and 7.05 years $(\mathrm{SD}=0.53)$, respectively. To answer the question whether video modeling affected social skills and subscales (social interaction, social participation, and appropriate social behaviors) of children with ASD, a Multivariate Analysis of Covariance (MANCOVA) was used. The descriptive statistics were compared with respect to each group's scores on the social interaction, social participation, appropriate social behaviors and social skills. Mean scores and standard deviation for each group were used as an overall group index (Table 2).

Multivariate Analysis of Covariance (MANCOVA) was used due to the presence of an independent variable and four dependent variables (social interaction, social participation, appropriate social behaviors, and total social skills) and moderate Pre-test effect. After checking and confirmation of normality of the study variables, Box's test approved equality of variance- covariance $(\mathrm{P}>0.05)$. Also variance equality assumption was approved by using Leven's test $(\mathrm{P}>0.05)$; therefore, MANCOVA test can be used. The overall Wilk's lambda was significant, $\mathrm{F}=1.627, \mathrm{P}=0.005$, indicating that experimental and control groups had significant difference, at least in one of

Table 2. Descriptive statistics for social skills and subscales

\begin{tabular}{|c|c|c|c|}
\hline \multirow{2}{*}{ Subscales } & \multirow{2}{*}{ Situation } & \multicolumn{2}{|c|}{ Mean士SD } \\
\hline & & Experimental & Control \\
\hline \multirow{2}{*}{ Social interaction } & Pre-test & $20.63 \pm 2.53$ & $20.84 \pm 3.11$ \\
\hline & Post-test & $34.82 \pm 3.08$ & $21.02 \pm 2.61$ \\
\hline \multirow{2}{*}{ Social participation } & Pre-test & $18.85 \pm 2.32$ & $17.95 \pm 2.14$ \\
\hline & Post-test & $27.99 \pm 2.38$ & $18.08 \pm 2.25$ \\
\hline \multirow{3}{*}{ Appropriate social beha } & Pre-test & $17.86 \pm 1.98$ & $18.63 \pm 2.02$ \\
\hline & & & \\
\hline & Post-test & $23.98 \pm 2.32$ & $18.01 \pm 2.06$ \\
\hline \multirow{3}{*}{ Total social skills } & Pre-test & $19.11 \pm 3.28$ & $19.14 \pm 3.11$ \\
\hline & & & \\
\hline & Post-test & $28.07 \pm 3.19$ & $19.03 \pm 3.24$ \\
\hline
\end{tabular}


Table 3. Multivariate analysis of covariance summary

\begin{tabular}{|c|c|c|c|c|c|c|c|}
\hline Source & Depended Variable & SS & DF & MS & $\mathbf{F}$ & Sig & $2 \eta$ \\
\hline \multirow{4}{*}{ Pre-test } & Social interaction & 36.147 & 1 & 36.147 & 6.349 & $0.005>$ & 0.19 \\
\hline & Social participation & 24.071 & 1 & 24.071 & 2.555 & $0.05>$ & 0.11 \\
\hline & Appropriate social behaviors & 25.368 & 1 & 25.368 & 3.867 & $0.005>$ & 0.18 \\
\hline & Total social skills & 28.436 & 1 & 28.436 & 5.802 & $0.005>$ & 0.17 \\
\hline \multirow{4}{*}{ Group } & Social interaction & 83.254 & 1 & 83.254 & 27.537 & $0.0001>$ & 0.57 \\
\hline & Social participation & 91.682 & 1 & 91.682 & 30.159 & $0.0001>$ & 0.62 \\
\hline & Appropriate social behaviors & 77.943 & 1 & 77.943 & 25.661 & $0.0001>$ & 0.55 \\
\hline & Total social skills & 84.167 & 1 & 84.167 & 28.170 & $0.0001>$ & 0.59 \\
\hline
\end{tabular}

the variables. In order to determine differences among scores of social skills and social interaction, social participation and appropriate social behaviors subscales between experimental and control groups, MANCOVA was used, which its results are shown in Table 3.

According to Table 3, intervention had positive and significant effect on post-test scores and there was significant difference among scores of social interaction, social participation, appropriate social behaviors, and total social skills between experimental and control groups $(\mathrm{P}<0.0001)$. As can be observed in Table 3, the results of MANCOVA showed that video modeling had positive and significant effect on the social interaction $(\mathrm{F}=27.537$, $\mathrm{P}<0.0001$ ), social participation $(\mathrm{F}=30.159, \mathrm{P}<0.0001)$, appropriate social behaviors $(\mathrm{F}=25.661, \mathrm{P}<0.0001)$ and total social skills $(\mathrm{F}=28.170, \mathrm{P}<0.0001)$.

\section{Discussion}

The present study aimed at examining the effect of video modeling on the social skills of children with ASD. Also, the current study evaluated the effectiveness of video modeling on social interaction, social participation, and appropriate social behaviors of children with DS into two groups (experimental and control) in the Pre-test and post-test.

The present study supported the effectiveness of video modeling on social interaction, social participation, appropriate social behaviors, and social skills of children with ASD. The present study result was similar to those of Matson (2009) that stated many children with ASD may better attend to a model presented in a video clip than a live model demonstrating the skill. Moreover, the present study result was similar to those of Besler et al. (2016) that investigated the effect of video modeling on children.

It can be said that ASD encompasses a group of disorders that can significantly impact behavior, social functioning, and social skills. Individuals diagnosed with ASD exhibit impaired or abnormal development in the social interaction, communication, and language, and also show a limited amount of activity and interests (Ross, 2007). Social interaction skills center on increasing the frequency and competency in social interaction. Skills that may be taught can include initiating or responding to other students (verbally, physically, or gesturally), maintaining conversations, offering to help, asking and answering questions, requesting information from others, and interacting in games (Bellini, Peters, Benner \& Hopf, 2007).

On the other and, video modeling is investigated for more than two decades as an effective method to teach a variety of behaviors to persons with ASD. This includes play skills, functional living skills, social behaviors, academic skills, and conversational skills (Besler \& et al., 2016). Also, video modeling is documented in the literature as being an effective technology to teach a variety of skills to individuals with ASD. It seems feasible that video modeling is appropriate to teach social skills as well (Matson, 2009).

In fact, the limited repertoires of social skills of children with ASD affect the ability to form and maintain friendships (Locke, Ishijima, Kasari, \& London, 2010). Lack of appropriate social skills is identified as a critical component of educational programming; the Individu- 
als with Disabilities Education Act (IDEA) stresses that educational goals for children with ASD should include the development of social skills (Chen, Bundy, Cordier, Chien, \& Einfeld, 2016). In addition, supporters of observational learning theory claim that video modeling should be used as a tool to teach self-care, communication, and social skills (Wong et al., 2015).

Although individuals with ASD tend to have passive activities (such as isolated play and parallel play), and they are less active compared with their peers, but video modeling is an intervention based on the theory of learning by observation and is used to learn new behaviors or change the existing behaviors (Delano, 2007; Nikopoulos \& Keenan, 2007). Video modeling addresses the limitations of scripts and cues by eliminating the requirements of reading ability, functioning level, and age. Moreover, video modeling is associated with additional advantages such as cost efficiency, rapid learning, promotion of generalization, and ability to present an entire conversation without the need of fading (Wong et al., 2015). Therefore, it is expected that video modeling leads to improving social skills, social interaction, social participation and appropriate social behaviors of children with ASD.

Several limitations of the current study should be noted. First, the nature of working with ASD children was inconsistent. It was difficult to ascertain development of children with ASD in stereotyped behaviors, communication, and social interaction. Demographic information indicated thad limited attention was paid to race and ethnicity. These limitations made it difficult to generalize the findings of the study to the general population, another limitation was the small sample size. Moreover, due to time limitation, there was no opportunity for follow up. Recommendations for other study this research created many opportunities for other study. First, the present study could be expanded to larger groups. Also, the video modeling program emphasizes on observing and learning appropriate behaviors or changing the existing behaviors, which provide opportunities to demonstrate communication and social interaction.

\section{Ethical Considerations}

\section{Compliance with ethical guidelines}

The present study was approved by the Human Ethics Research Committee of Exceptional Education Organization in Tehran, Iran.

\section{Funding}

This research did not receive any specific grant from funding agencies in the public, commercial, or not-for-profit sectors.

\section{Authors' contributions}

Conceptualization, investigation, Funding acquisition: all author; Methodology: Mohammad Ashori; Writing-original draft: Seyyedeh Somayyeh Jalil-Abkenar; Writing-review \& editing: Mohammad Ashori; Resources: Seyyedeh Somayyeh Jalil-Abkenar; Supervision: Mohammad Ashori.

\section{Conflict of interest}

Authors declared no conflict of interest.

\section{References}

Ahmadi, S., Safari, T., Hemmatian, M., \& Khalili, Z. (2011) [The psychometric properties of Gilliam Autism Rating Scale (GARS) (Persian)]. Research in Cognitive and Behavioral Sciences, 1(1), 87-104.

Alberto, P. A., Cihak, D. F., \& Gama, R. I. (2005). Use of static picture prompts versus video modeling during simulation instruction. Research in Developmental Disabilities, 26(4), 327-39. [DOI:10.1016/j.ridd.2004.11.002] [PMID]

Aldi, C., Crigler, A., Kates-McElrath, K., Long, B., Smith, H., \& Rehak, K., et al., (2016). Examining the effects of video modeling and prompts to teach activities of daily living skills. Behavior Analysis in Practice, 9(4), 38-8. [DOI:10.1007/s40617-0160127-y] [PMID] [PMCID]

American Psychiatric Association (2013). Diagnostic and Statistical Manual of Mental Disorders (DSM-V). Philadelphia: American Psychiatric Association.

Barnard-Brak, L., Ivey-Hatz, J., Kris Ward, A., \& Wei, T. (2014). Self-regulation and social interaction skills among children with autism across time. Advances in Mental Health and Intellectual Disabilities, 8(4), 271-9. [DOI:10.1108/AMHID-12-2012-0007]

Bellini, S., \& Hopf, A. (2007). The development of the autism social skills profile: A preliminary analysis of psychometric properties. Focus on Autism and Other Developmental Disabilities, 22(2), 80-7. [DOI:10.1177/10883576070220020801]

Bellini, S., Peters, J. K., Benner, L., \& Hopf, A. (2007). A metaanalysis of school-based social skills interventions for children with autism spectrum disorders. Remedial and Special Education, 28(3), 153-62. [DOI:10.1177/07419325070280030401]

Besler, F., \& Kurt, O. (2016). Effectiveness of video modeling provided by mothers in teaching play skills to children with autism. Educational Sciences, 16(1), 209-30. [DOI:10.12738/ estp.2016.1.0273] 
Bottini, S. (2018). Social reward processing in individuals with autism spectrum disorder: A systematic review of the social motivation hypothesis. Research in Autism Spectrum Disorders, 45, 9-26. [DOI:10.1016/j.rasd.2017.10.001]

Butchart, M., Long, J. J., Brown, M., McMillan, A., Bain, J., \& Karatzias, T. (2017). Autism and visual impairment: A review of the literature. Review Journal of Autism and Developmental Disorders, 4(2), 118-31. [DOI:10.1007/s40489-016-0101-1]

Chen, Y. W., Bundy, A., Cordier, R., Chien, Y. L., \& Einfeld, S. (2016). The experience of social participation in everyday contexts among individuals with autism spectrum disorders: An experience sampling study. Journal of Autism and Developmental Disorders, 46(4), 1403-14. [DOI:10.1007/s10803-015-2682-4] [PMID]

Delano, M. E. (2007). Video modeling interventions for individuals with autism. Remedial and Special Education, 28(1), 33-42. [DOI:10.1177/07419325070280010401]

Kagohara, D. M., Achmadi, D., Van der Meer, L., Lancioni, G. E., O'Reilly, M. F., Lang, R., et al., (2013). Teaching two students with Asperger syndrome to greet adults using social stories ${ }^{\mathrm{TM}}$ and video modeling. Journal of Developmental and Physical Disabilities, 25(2), 241-51. [DOI:10.1007/s10882-012-9300-6]

Locke, J., Ishijima, E. H., Kasari, C., \& London, N. (2010). Loneliness, friendship quality and the social networks of adolescents with high-functioning autism in an inclusive school setting. Journal of Research in Special Educational Needs, 10(2), 74-81. [DOI:10.1111/j.1471-3802.2010.01148.x]

Loomes, R., Hull, L., \& Mandy, W. P. L. (2017). What is the maleto-female ratio in autism spectrum disorder? A systematic review and meta-analysis. Journal of the American Academy of Child \& Adolescent Psychiatry, 56(6), 466-74. [DOI:10.1016/j. jaac.2017.03.013] [PMID]

Maddox, B. B., Miyazaki, Y., \& White, S. W. (2017). Long-term effects of CBT on social impairment in adolescents with ASD Journal of Autism and Developmental Disorders, 47(12), 3872-82. [DOI:10.1007/s10803-016-2779-4] [PMID]

Matson, J. L., Dempsey, T., \& LoVullo, S. V. (2009). Characteristics of social skills for adults with intellectual disability, autism and PDD-NOS. Research in Autism Spectrum Disorders, 3(1), 207-13. [DOI:10.1016/j.rasd.2008.05.006]

Moghim Islam, P., Pourmohamadreza-Tajrishi, M., \& Haghgoo, H. (2014). [The effect of reciprocal imitation training on social skills of children with autism (Persian)]. Journal of Rehabilitation, 14(6), 59-67.

Nikopoulos, C. K., \& Keenan, M. (2007). Using video modeling to teach complex social sequences to children with autism. Journal of Autism and Developmental Disorders, 37(4), 678-93. [DOI:10.1007/s10803-006-0195-x] [PMID]

Ross, R. K. (2007). Beyond ASD treatment: The application of applied behavior analysis in the treatment of emotional and psychological disorders. International Journal of Behavioral Consultation and Therapy, 4(4), 528-36. [DOI:10.1037/h0100826]

Samadi, S. A., \& McConkey, R. (2014). The utility of the Gilliam autism rating scale for identifying Iranian children with autism. Disability and Rehabilitation, 36(6), 452-6. [DOI:10.3109 /09638288.2013.797514] [PMID]

Spain, D., Sin, J., Linder, K. B., McMahon, J., \& Happé, F. (2018). Social anxiety in autism spectrum disorder: A systematic review. Research in Autism Spectrum Disorders, 52, 51-68. [DOI:10.1016/j.rasd.2018.04.007]

Wong, C., Odom, S. L., Hume, K. A., Cox, A. W., Fettig, A., Kucharczyk, S., et al., (2015). Evidence-based practices for children, youth, and young adults with autism spectrum disorder: A comprehensive review. Journal of Autism and Developmental Disorders, 45(7), 1951-66. [DOI:10.1007/s10803-014 2351-z] [PMID] 